\title{
Lifestyle and psychosocial factors and a decline in competence in daily living among Japanese early elderly people: from an age-specified community-based cohort study (NISSIN project)
}

\author{
Satoe Okabayashi ${ }^{1 *}$ (D, Takashi Kawamura', Kenji Wakai ${ }^{2}$, Masahiko Ando ${ }^{3}$, Kazuyo Tsushita $^{4}$, Hideki Ohira ${ }^{5}$, \\ Shigekazu Ukawa ${ }^{6,7}$ and Akiko Tamakoshi ${ }^{7}$
}

\begin{abstract}
Background: To let the early elderly live well, understanding how lifestyle and psychosocial factors related to a decline in competence in daily living is important.

Methods: We investigated the associations between lifestyle and psychosocial factors at age 64 years and a decline in the Tokyo Metropolitan Institute of Gerontology Index of Competence score of $\geq 2$ points at age 70 years among the participants in comprehensive medical check-ups living in a city in Japan. Multivariable logistic regression analyses were performed separately for men and women.

Results: Of the 1113 eligible men and 1203 eligible women, 110 men and 80 women showed a deteriorated competence in daily living during the 6 years. In men, risk was increased with $\geq 2$ nighttime awakenings (multivariable odds ratio [mOR] 2.14, 95\% confidence interval [Cl] 1.19-3.86) and living alone ( $\mathrm{mOR} 4.68,95 \% \mathrm{Cl} 1.22-18.0$ ), whereas risk was significantly decreased with a medium or fast gait (mOR 0.37 and $0.21,95 \% \mathrm{Cl} 0.21-0.67$ and $0.08-0.58$ ) and high academic achievement (mOR 0.32 and $0.43,95 \% \mathrm{Cl} 0.19-0.53$ and 0.25-0.72). In women, risk was decreased with high life satisfaction (mOR 0.39, 95\% Cl 0.16-0.91) and participation in community activities (mOR 0.50, 95\% Cl 0.29-0.86) but increased with depressive mood (mOR 1.86, 95\% Cl 1.09-3.18).
\end{abstract}

Conclusion: Living alone for men and low life satisfaction for women at age 64 years were markedly associated with the risk of a subsequent declining competence in daily living.

Keywords: Aging, Cohort studies, Lifestyle, Physical functional performance, Risk factors

\section{Background}

Many developed countries in the world are faced with aging populations. The estimated proportion of people aged $\geq 60$ years will increase from $12.3 \%$ in 2015 to $21.5 \%$ in 2050 in the world [1]. Especially in Japan, the proportion of people aged $\geq 65$ years is rapidly increasing year by year and will reach $30 \%$ of the population by 2025 [2]. The country is thus considered to be a

\footnotetext{
* Correspondence: okabayashi.satoe.8c@kyoto-u.ac.jp

${ }^{1}$ Kyoto University Health Service, Yoshida-Honmachi, Sakyo-ku, Kyoto 606-8501, Japan

Full list of author information is available at the end of the article
}

forerunner of an ever-aging world. Because such an aging population is unprecedented, accommodation to the coming situation is important and urgently required.

Turning 65 is considered to be one of the biggest milestones in life. When people reach this age in Japan, they usually retire from their job if employed, start to draw a state pension, and earn the right to receive nursing care from the social insurance system, regardless of their working status [3]. Such a social system is similar to that of European countries.

From a biological standpoint, most elderly individuals around 65 years of age who live in the community are 
independent in their activities of daily living (ADL), including eating, dressing, bathing, toileting, transferring, and continence $[4,5]$. However, some individuals start to show a declined incompetence in daily living, known as instrumental activities of daily living (IADL), which are necessary to live in the community [5]. IADL directly affects subsequent independent life and well-being in community-dwelling elderly individuals [6], and its decline predicts mortality [7]. It is thus necessary to know the risk or preventive factors related to a decline in competence in daily living at around 65 years of age to help people to live well in later life.

Recent studies have reported several factors causing such a decline in IADL [8-16]. However, the participants in most previous studies were aged $\geq 65$ years, with considerable variability in the age range and with few focusing on the early elderly. Because factors associated with a decline in competence in daily living are expected to differ by age, as with mortality $[7,17,18]$, we established a cohort of community-dwelling elders with a specified baseline age of 64 years, and we investigated the lifestyle and psychosocial risk and preventive factors in the early elderly related to a decline in competence in daily living.

\section{Methods}

\section{Study design}

The study population was extracted from the New Integrated Suburban Seniority Investigation (NISSIN) project, a community-based prospective cohort study of Japanese elderly individuals of a specified age. Project rationale and design are described elsewhere $[19,20]$. Briefly, residents of Nisshin City, Aichi Prefecture, who were 64 years old on January 1 of the respective years from 1996 to 2005 were invited to undergo free-of-charge comprehensive medical check-ups consisted of somatometry, blood tests, and a detailed self-administered questionnaire [20]; 3073 participants (1548 men and 1525 women, $43.9 \%$ of eligible residents) who provided informed consent were enrolled in the cohort. They were invited to undergo comprehensive medical check-ups again at age 70 years from 2002 to 2011 . Outcomes were measured by the second medical check-ups, home visits by municipal public health nurses, the insurance system for long-term care, or vital statistics.

\section{Study participants}

The subjects of this study were those persons who participated in the medical check-ups at age 64 and whose competence in daily living was not in decline at this baseline.

\section{Indicator of competence in daily living}

As an indicator of competence in daily living, we used the Tokyo Metropolitan Institute of Gerontology Index of Competence (TMIG-IC), a self-administered questionnaire representing the higher dimensional competence in daily living $[9,21]$. The TMIG-IC is a multidimensional 13-item index that includes three sublevels of competence: instrumental self-maintenance, intellectual activity, and social role. The response to each item is "yes (score 1)" or "no (score 0)". The higher the total score, the higher the competence in daily living. The baseline TMIG-IC was measured by the medical check-ups at age 64 years, and follow-up TMIG-IC was measured by the medical check-ups or home visits of public health nurses at age 70 years.

\section{Lifestyle and psychosocial factors}

From the various factors screened at age 64 years, we extracted the lifestyle and psychosocial factors from the self-administered questionnaire that were less missed $(<10 \%)$ and were deemed to be biologically associated with the decline in the competence of daily living. They included depressive tendency (shorter version of the Geriatric Depression Scale [GDS]) [22, 23], mental stress or strain, life satisfaction status (life satisfaction index-K) [20], frequency of nighttime awakening, smoking status (never, past, current), frequency of alcohol intake per week, amount of ethanol intake per drink, daily walking time, gait speed, and sleeping hours. Also obtained was information on self-reported working status (current worker or not), participation in community activities, academic background, marital status, and number of family members living together.

\section{Statistical analysis}

We treated a total TMIG-IC score of $\geq 11$ points at age 64 years as a preserved competence in daily living. The main outcome was a decline in the competence in daily living of $\geq 2$ points in the TMIG-IC score from 64 to 70 years of age. For the analyses, a score of the shorter version of the GDS $\geq 6$ was treated as depressive tendency [22, 23]. Life satisfaction status in the life satisfaction index-K questionnaire was divided into three categories $(\geq 7,5$ or $6, \leq 4)$, and the self-reported frequency of nighttime awakening was also trisected (seldom, about once, about $\geq 2$ ). The following self-reported daily habits were divided into three categories: amount of daily ethanol intake calculated based on the type of beverage, amount per drink, and frequency per week (seldom, $<23$ $\mathrm{g}, \geq 23 \mathrm{~g})$, daily walking time ( $<30 \mathrm{~min}, 30 \mathrm{~min}-1 \mathrm{~h}, \geq 1 \mathrm{~h}$ ), and daily sleeping hours $(<6 \mathrm{~h}, 6-8 \mathrm{~h}, \geq 8 \mathrm{~h})$. The activities and participation status in the self-administered questionnaire were treated as follows: working status was dichotomized (current worker or not), and community activity participation was also divided into two categories (participation in $\geq 1$ community activity or not) [24]. The academic background was trisected (junior high school, senior high school, junior college, or higher education), 
marital status was dichotomized (currently married or not), and the number of family members living together was divided into three categories (none, $1, \geq 2$ ).

Missing variables were replaced with the mean value for continuous data and with the most frequently chosen category for the categorical data in each sex. Baseline characteristics were compared between the sexes using Pearson's chi-square test or Fisher's exact test.

To reveal the associations between the baseline lifestyle and psychosocial factors and a subsequent decline in competence in daily living, univariable and multivariable logistic regression analyses were performed in men and women separately and odds ratios (ORs) and their 95\% confidence intervals (CIs) were calculated. In the multivariable analysis, we incorporated lifestyle and psychosocial variables any category of which was statistically significant or marginally significant $(P<.1)$ in univariable analyses considering the possibility of multicollinearity. Here, we adjusted for the participation year and fundamental medical factors (the present illness of hypertension and past history of cerebrovascular disease in men, no factors in women) that were significantly associated with the outcome in the screening analyses. A trend test was performed when a variable had three ordinal categories. As a sensitivity analysis, we performed analyses in the same way but limited to participants whose baseline TMIG-IC score was 13, the perfect score. All tests of significance were two-tailed, and $P$ values of $<.05$ were considered significant. STATA 12.1 software (STATA Corporation, College Station, TX) was used for statistical analyses.

\section{Ethical considerations}

For informed consent, an opt-out approach was adopted from 1996 to 2001 and individual written informed consent was obtained thereafter $[19,20]$. The study was approved by the Ethics Committees of Nagoya University Graduate School of Medicine, the National Center for Geriatrics and Gerontology of Japan, Aichi Medical University of Medicine, and Hokkaido University Graduate School of Medicine.

\section{Results}

The study flowchart is shown in Fig. 1. A total of 3073 residents (1548 men and 1525 women) participated in the medical check-ups and consented to data use at age 64 years. We excluded 15 participants $(6$ men and 9 women) who did not complete the TMIG-IC questionnaire at age 64 years and 356 participants (221 men and 135 women) whose TMIG-IC score was $<11$ at age 64 years from this study. Among the 2702 eligible subjects (1321 men and 1381 women), 99 (69 men and 30 women) died and 125 (62 men and 63 women) moved out of the area before reaching age 70 years. After further excluding 162 (77 men and 85 women) who did

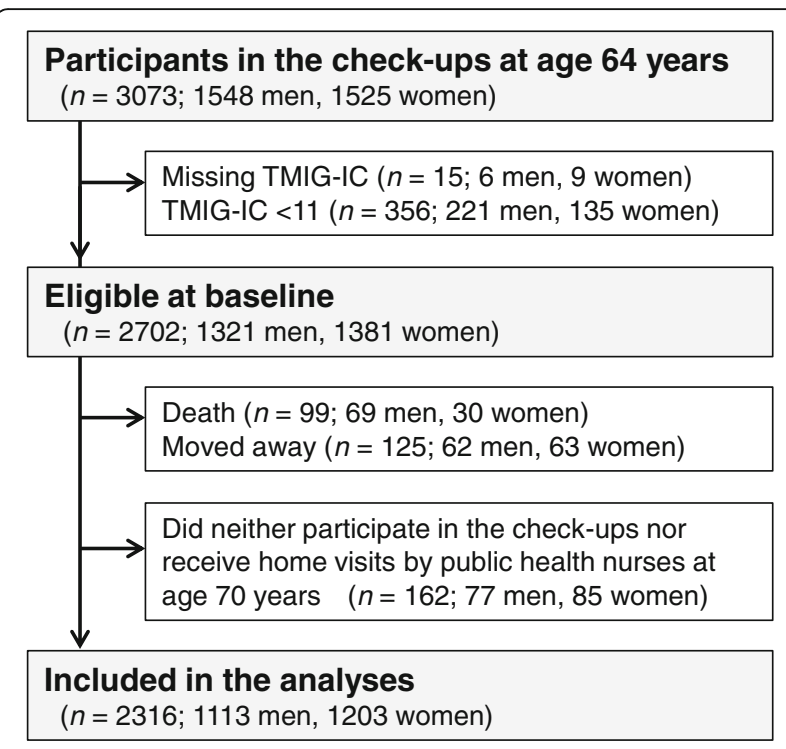

Fig. 1 The flow of the study subjects

neither undergo the check-ups nor receive home visits by public health nurses at age 70 years, this left 2316 (1113 men and 1203 women) for analyses.

Baseline lifestyle and psychosocial characteristics of the participants according to sex are shown in Table 1. The proportion of missing data was $<0.3 \%$, except for the frequency of alcohol intake (3.3\%). Women were more likely to be depressed and feel stressed than men, but no significant sex difference was found in life satisfaction. The proportion of current smoking, amount of daily ethanol intake, proportions of current working, high final educational attainments, and married status were greater in men, whereas that of living alone was smaller. Walking time was longer but sleeping time was shorter in women.

Table 2 shows the associations of lifestyle and psychosocial factors at age 64 years with a subsequent decline in competence in daily living by univariable and multivariable analyses in men. Of the eligible male participants, 110 (9.9\%) showed a deteriorated competence in daily living from age 64 to 70 years. In the univariable analyses, depressive mood, life satisfaction, nighttime awakening, daily ethanol intake, regular exercise, gait speed, final educational status, marital status, and number of family members living together were significantly associated with a decline in competence in daily living. Because of the multicollinearity between marital status and the number of family members living together, we adopted the latter in the multivariable analysis. In the multivariable analysis, risk was significantly increased with $\geq 2$ nighttime awakenings (OR 2.14, 95\% CI 1.193.86 ) and living alone (OR 4.68, 95\% CI 1.22-18.0). Risk was significantly decreased with a medium or fast gait 
Table 1 Lifestyle and psychosocial characteristics of participants at age 64 years

\begin{tabular}{|c|c|c|c|}
\hline & $\begin{array}{l}\text { Men } \\
(n=1113)\end{array}$ & $\begin{array}{l}\text { Women } \\
(n=1203)\end{array}$ & $P$ value \\
\hline \multicolumn{4}{|l|}{ Mental condition } \\
\hline Depressive mood ${ }^{\dagger}$ & $172(15.5)$ & $259(21.6)$ & 0.001 \\
\hline \multicolumn{4}{|l|}{ Mental strain } \\
\hline Seldom & $610(55.1)$ & $423(35.2)$ & $<0.001$ \\
\hline Sometimes & $455(41.1)$ & $686(57.1)$ & \\
\hline Always & $42(3.8)$ & $93(7.7)$ & \\
\hline \multicolumn{4}{|l|}{ Life satisfaction $^{\ddagger}$} \\
\hline $\operatorname{Low}(\leq 4)$ & $392(35.3)$ & $441(36.7)$ & 0.39 \\
\hline Medium (5-6) & $422(38.0)$ & $424(35.3)$ & \\
\hline High ( $\geq 7)$ & $296(26.7)$ & $337(28.0)$ & \\
\hline \multicolumn{4}{|l|}{ Nighttime awakening } \\
\hline Seldom & $250(22.5)$ & $249(20.7)$ & 0.146 \\
\hline Once & $463(41.6)$ & $549(45.6)$ & \\
\hline Twice or more & $400(35.9)$ & $405(33.7)$ & \\
\hline \multicolumn{4}{|l|}{ Daily habits } \\
\hline \multicolumn{4}{|l|}{ Smoking } \\
\hline Never & $224(20.1)$ & $\begin{array}{l}1106 \\
(91.9)\end{array}$ & $<0.001$ \\
\hline Past & $547(49.2)$ & $62(5.2)$ & \\
\hline Current & $341(30.7)$ & $35(2.9)$ & \\
\hline \multicolumn{4}{|l|}{ Daily ethanol intake $e^{\S}$} \\
\hline Seldom & 341 (31.7) & $954(82.0)$ & $<0.001$ \\
\hline$\leq 23 \mathrm{~g}$ & $460(42.8)$ & $198(17.0)$ & \\
\hline$>23 \mathrm{~g}$ & $274(25.5)$ & $12(1.0)$ & \\
\hline \multicolumn{4}{|l|}{ Regular exercise } \\
\hline Seldom & $400(36.0)$ & $483(40.2)$ & 0.081 \\
\hline$<1 /$ week & $108(9.7)$ & $98(8.2)$ & \\
\hline$\geq 1 /$ week & $604(54.3)$ & $621(51.7)$ & \\
\hline \multicolumn{4}{|l|}{ Daily walking time } \\
\hline$<30 \min$ & $182(16.4)$ & $96(8.1)$ & $<0.001$ \\
\hline $30 \mathrm{~min}$ to $1 \mathrm{~h}$ & $389(35.1)$ & $305(25.6)$ & \\
\hline$\geq 1 \mathrm{~h}$ & 539 (48.6) & $792(66.4)$ & \\
\hline \multicolumn{4}{|l|}{ Gait speed } \\
\hline Slow & $97(8.7)$ & 155 (12.9) & 0.003 \\
\hline Medium & $872(78.4)$ & $882(73.4)$ & \\
\hline Fast & $143(12.9)$ & $164(13.7)$ & \\
\hline \multicolumn{4}{|l|}{ Daily sleeping hours } \\
\hline$<6 h$ & $69(6.2)$ & $154(12.8)$ & $<0.001$ \\
\hline $6-8 h$ & $714(64.2)$ & $836(64.5)$ & \\
\hline $8 \mathrm{~h}$ & $330(28.7)$ & $213(17.7)$ & \\
\hline \multicolumn{4}{|l|}{ Social activities } \\
\hline Current working & $639(58.1)$ & 309 (25.9) & $<0.001$ \\
\hline Participation in community & $904(81.2)$ & 1021 & 0.019 \\
\hline
\end{tabular}

Table 1 Lifestyle and psychosocial characteristics of participants at age 64 years (Continued)

\begin{tabular}{llll}
\hline & $\begin{array}{l}\text { Men } \\
(n=1113)\end{array}$ & $\begin{array}{l}\text { Women } \\
(n=1203)\end{array}$ & $P$ value \\
\hline activities & & $(84.9)$ & \\
Environment & & & \\
$\quad$ Final educational status & & & \\
$\quad$ Junior high school & $282(25.4)$ & $384(32.0)$ & $<0.001$ \\
$\quad$ Senior high school & $452(40.7)$ & $617(51.4)$ & \\
$\quad$ Junior college or higher & $376(33.9)$ & $199(16.6)$ & \\
Marital status & & & \\
$\quad$ Never, widowed, or divorced & $42(3.8)$ & $196(16.4)$ & $<0.001$ \\
Presently married & 1071 & 1003 & \\
& $(96.2)$ & $(83.7)$ & \\
Number of family members living together & & \\
0 & $13(1.2)$ & $74(6.4)$ & $<0.001$ \\
1 & $540(48.3)$ & $611(52.5)$ & \\
$\geq 2$ & $543(49.5)$ & $478(41.1)$ & \\
\hline
\end{tabular}

Values are expressed as number (percentage). Percentage was calculated by excluding missing data

${ }^{\dagger}$ Participants whose score on the Geriatric Depression Scale was 6 or more ${ }^{\ddagger}$ Life satisfaction index-K

${ }^{\S}$ Mean daily ethanol intake was calculated from the type, amount, and frequency of alcoholic beverages

(compared with slow gait, OR 0.37, 95\% CI $0.21-0.67$ and OR $0.21,95 \%$ CI $0.08-0.58$, respectively; $P_{\text {trend }}<.001$ ) and high final educational status (senior high school, junior college, or higher education; compared with junior high school, OR 0.32, 95\% CI $0.19-0.53$ and OR $0.43,95 \%$ CI $0.25-0.72$, respectively; $\left.P_{\text {trend }}=.001\right)$. A strong association was found between living alone and a decline in competence in daily living. Of the 13 men living alone, 9 were widowed, 2 were divorced, 1 was currently married, and 1 had never married. Indeed, 4 out of the 13 single men (3 widowed and 1 had never married) showed a decreased competence in daily living at age 70 years.

Table 3 shows the associations of lifestyle and psychosocial factors at age 64 years with a subsequent decline in competence in daily living by univariable and multivariable analyses in women. Of the eligible female participants, $80(6.7 \%)$ showed a deteriorated competence in daily living over the 6 years. In the univariable analyses, a decline was significantly associated with depressive mood, mental stress status, life satisfaction, nighttime awakening, regular exercise, gait speed, daily sleeping hours, participation in community activities, and final educational status. There was no significant multicollinearity among these factors. In the multivariable analysis, the risk of reduced competence in daily living was significantly increased with depressive mood (OR 1.86, 95\% CI 1.09-3.18) and significantly decreased with high life satisfaction (OR 0.39, 95\% CI 0.16-0.91) and 
Table 2 Association of lifestyle/psychosocial factors at age 64 years with reduced competence in daily living at age 70 years (males)

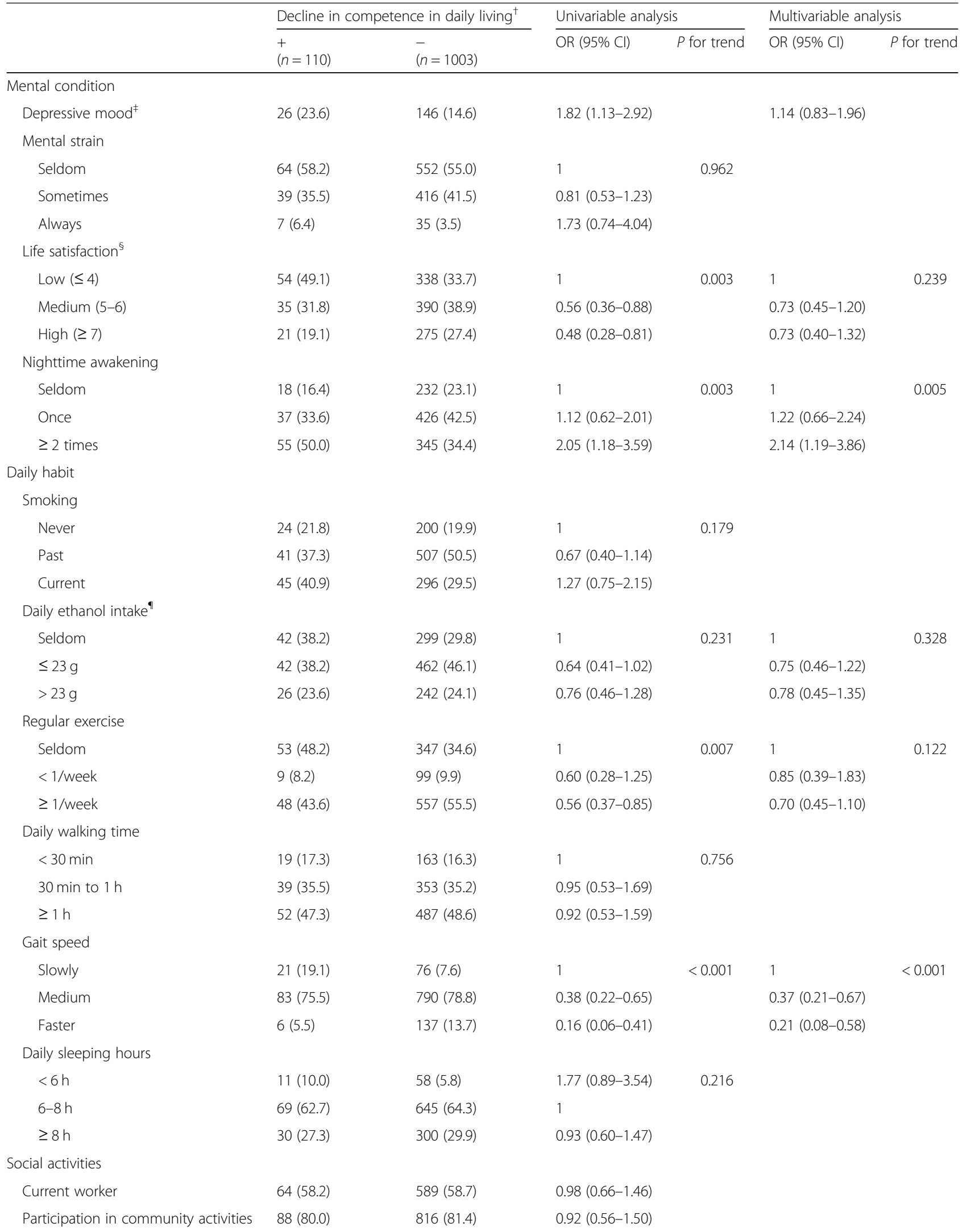


Table 2 Association of lifestyle/psychosocial factors at age 64 years with reduced competence in daily living at age 70 years (males) (Continued)

\begin{tabular}{|c|c|c|c|c|c|c|}
\hline & \multicolumn{2}{|c|}{ Decline in competence in daily living $^{\dagger}$} & \multicolumn{2}{|c|}{ Univariable analysis } & \multicolumn{2}{|c|}{ Multivariable analysis } \\
\hline & $\begin{array}{l}+ \\
(n=110)\end{array}$ & $\begin{array}{l}- \\
(n=1003)\end{array}$ & OR $(95 \% \mathrm{Cl})$ & $P$ for trend & OR $(95 \% \mathrm{Cl})$ & $P$ for trend \\
\hline \multicolumn{7}{|l|}{ Environment } \\
\hline \multicolumn{7}{|l|}{ Final educational status } \\
\hline Junior high school & $52(47.3)$ & $230(22.9)$ & 1 & $<0.001$ & 1 & 0.001 \\
\hline Senior high school & $29(26.4)$ & $425(42.4)$ & $0.30(0.19-0.49)$ & & $0.32(0.19-0.53)$ & \\
\hline Junior college or higher & $29(26.4)$ & $348(34.7)$ & $0.37(0.23-0.60)$ & & $0.43(0.25-0.72)$ & \\
\hline \multicolumn{7}{|l|}{ Marital status } \\
\hline Never, widowed, or divorced & $8(7.3)$ & $34(3.4)$ & 1 & & & \\
\hline Presently married & $102(92.7)$ & 969 (96.6) & $0.45(0.20-0.99)$ & & & \\
\hline \multicolumn{7}{|c|}{ Number of family members living together } \\
\hline 0 & $4(3.6)$ & $9(0.9)$ & $4.61(1.37-15.5)$ & 0.905 & $4.68(1.22-18.0)$ & 0.665 \\
\hline 1 & $49(44.5)$ & $508(50.6)$ & 1 & & 1 & \\
\hline$\geq 2$ & 57 (51.8) & $486(48.5)$ & $1.22(0.81-1.82)$ & & $1.09(0.71-1.67)$ & \\
\hline
\end{tabular}

$\mathrm{OR}, 95 \% \mathrm{Cl}$, and $P$ for trend were calculated by using imputation to provide the missing data. Multivariable analysis: adjusted for year of participation and history of hypertension or cerebrovascular disease

$O R$ odds ratio, $\mathrm{Cl}$ confidence interval

${ }^{\dagger}$ Reduced score on the Tokyo Metropolitan Institute of Gerontology Index of Competence of $\geq 2$ from 64 years of age

${ }^{\ddagger}$ Geriatric Depression Scale $\geq 6$

§Life satisfaction index-K

"Mean daily ethanol intake was calculated from the type, amount, and frequency of alcoholic beverages

participation in community activities (OR 0.50, 95\% CI $0.29-0.86)$. A decreased risk was marginally significantly associated with regular exercise ( $\geq 1$ time per week) (OR 0.63, 95\% CI 0.38-1.07).

When limited to participants whose TMIG-IC was 13 at age 64years, the associations of psychosocial factors at age 64 years with a subsequent decline in competence in daily living were essentially unaltered for both men and women.

\section{Discussion}

To our knowledge, this is the first study to show the risk and preventive factors in early elderly individuals related to a subsequent decline in competence in daily living. The strong point of this study is all the participants were the same age, 64 years old. By focusing the subjects' age at 64 years, we could overcome the limitation of the previous studies that the age was widely distributed which strongly affected the incidence of outcomes.

For men, living alone was associated with a low competence in daily living in previous cross-sectional studies only, which do not allow inference of causal relationships [25, 26]. Our cohort study showed a very strong association between living alone and a subsequent decline in competence in daily living, suggesting a cause-and-effect relationship. There may be two major reasons for this. First, men tend not to be familiar with cooking and are more likely to be indifferent with regard to nutritional practice [27-29]. Men who live alone, therefore, might not eat healthily, which would impact their health and affect their competence in daily living [29]. Second, men are less integrated within their social networks [30, 31]. A qualitative study speculated that Japanese elderly men tended to refuse to socialize widely because of embarrassment socializing with women but would be comfortable talking with small numbers of men in the same age bracket [32]. Men who live alone, therefore, might get less social support, leading to poor outcomes. Unfortunately, we could not analyze the decline in competence according to the reason such as marital status for living alone because of the small number of men in the respective reason categories.

Life satisfaction is well known to be related to functional ability $[33,34]$. Previous cohort studies also showed associations between life satisfaction and mortality in elderly people $[35,36]$. However, it is unknown whether the life satisfaction level modifies functional ability. Although their causal relationship is unclear, higher life satisfaction might induce relatively active health behaviors and prevent the deterioration in health status [36]. However, such an association was found only in women [35, 37]. According to the studies by Bowling and Grundy reporting life satisfaction and mortality, women's affinity with social networks would improve life satisfaction and play a protective role [35, 37]. Among Japanese elderly individuals, a larger number of friends and social activities also enhance life satisfaction in women but not 
Table 3 Association of lifestyle/psychosocial factors at age 64 years with reduced competence in daily living at age 70 years (females)

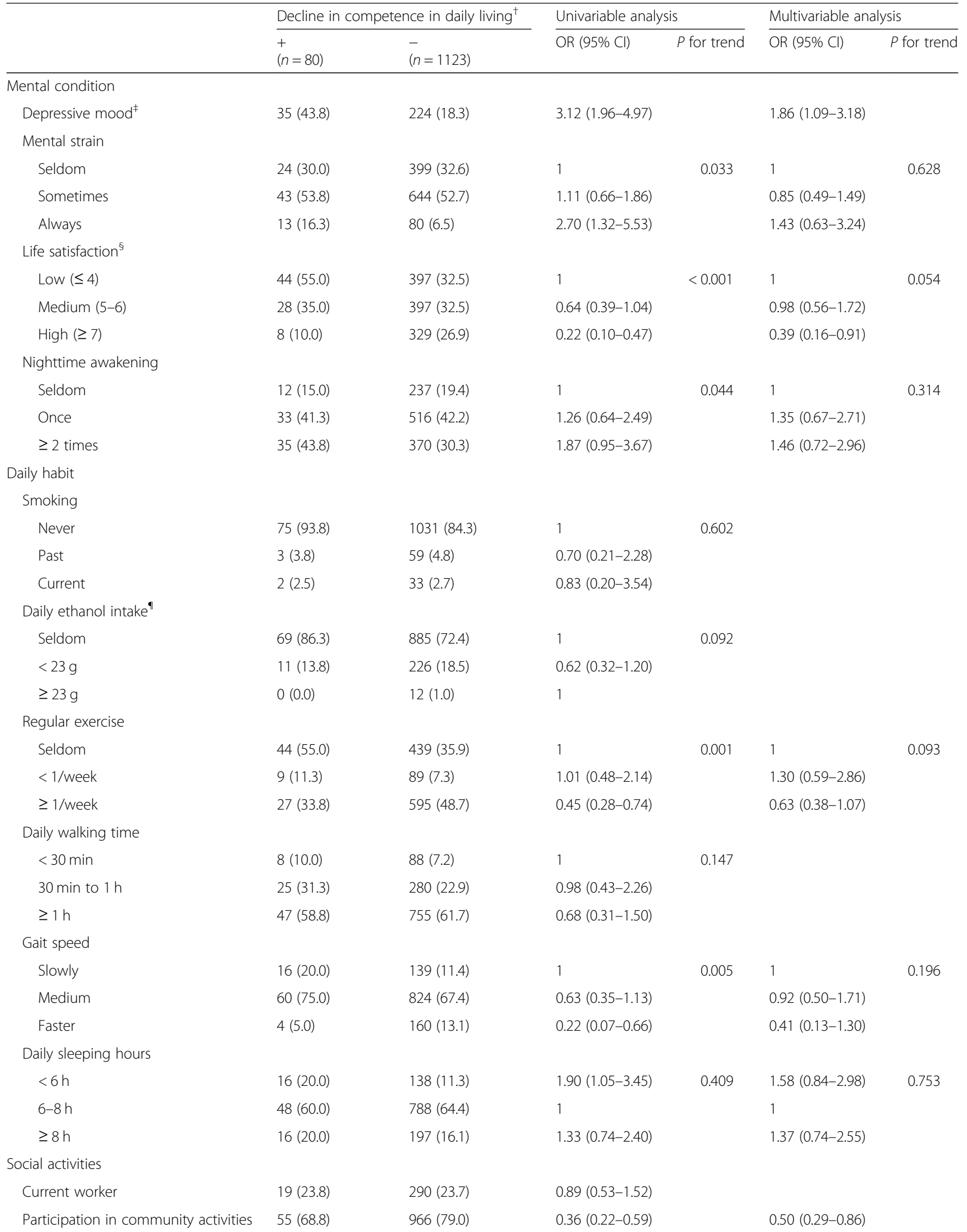


Table 3 Association of lifestyle/psychosocial factors at age 64 years with reduced competence in daily living at age 70 years (females) (Continued)

\begin{tabular}{|c|c|c|c|c|c|c|}
\hline & \multicolumn{2}{|c|}{ Decline in competence in daily living ${ }^{\dagger}$} & \multicolumn{2}{|c|}{ Univariable analysis } & \multicolumn{2}{|c|}{ Multivariable analysis } \\
\hline & $\begin{array}{l}+ \\
(n=80)\end{array}$ & $\begin{array}{l}- \\
(n=1123)\end{array}$ & OR $(95 \% \mathrm{Cl})$ & $P$ for trend & OR $(95 \% \mathrm{Cl})$ & $P$ for trend \\
\hline \multicolumn{7}{|l|}{ Environment } \\
\hline \multicolumn{7}{|l|}{ Final educational status } \\
\hline Junior high school & $38(47.5)$ & $346(28.3)$ & 1 & 0.029 & 1 & 0.63 \\
\hline Senior high school & $29(36.3)$ & $588(48.1)$ & $0.45(0.27-0.74)$ & & $0.64(0.38-1.09)$ & \\
\hline Junior college or higher & $13(16.3)$ & $189(15.5)$ & $0.63(0.33-1.20)$ & & $1.04(0.52-2.10)$ & \\
\hline \multicolumn{7}{|l|}{ Marital status } \\
\hline Never, widowed, or divorced & $14(17.5)$ & $182(14.9)$ & 1 & & & \\
\hline Presently married & $66(82.5)$ & $941(76.9)$ & $0.91(0.50-1.66)$ & & & \\
\hline \multicolumn{7}{|c|}{ Number of family members living together } \\
\hline 0 & $5(6.3)$ & $69(5.6)$ & $1.02(0.39-2.67)$ & 0.979 & & \\
\hline 1 & $43(53.8)$ & $608(49.7)$ & 1 & & & \\
\hline$\geq 2$ & $32(40.0)$ & $466(38.1)$ & $0.89(0.63-1.63)$ & & & \\
\hline
\end{tabular}

$\mathrm{OR}, 95 \% \mathrm{Cl}$, and $P$ for trend were calculated by using imputation to provide the missing data. Multivariable analysis: adjusted for year of participation $O R$ odds ratio, $\mathrm{Cl}$ confidence interval

${ }^{\dagger}$ Reduced score on the Tokyo Metropolitan Institute of Gerontology Index of Competence of $\geq 2$ from 64 years of age

${ }^{\ddagger}$ Geriatric Depression Scale $\geq 6$

${ }^{\S}$ Life satisfaction index-K

"Mean daily ethanol intake was calculated from the type, amount, and frequency of alcoholic beverages

in men [38]. Hence, women are more sensitive to social relations than men.

The other findings that participation in community activities [8, 10-12], physical activity [8, 14], a smallto-moderate amount of ethanol intake $[8,15]$, and high academic achievement [16] were negatively associated with a decline in competence in daily living but that depressive mood $[8,39]$ and poor quality of sleep [13] were positively associated were consistent with those of previous cohort studies. However, those findings were obtained from older people with a wide age range. Here, we have provided new evidence obtained specifically from early elderly individuals that could help people to improve their well-being in later life. Moreover, most past studies evaluated simple IADL as the outcome. We used TMIG-IC, a more comprehensive scale including instrumental self-maintenance, intellectual activity, and social role, which allowed us to capture the delicate decline in competence in daily living.

There are three limitations to this study. Firstly, except the participants who died before age 70 years, $11.0 \%$ of the participants at baseline could not be followed at 70 years because they moved out $(4.8 \%)$ or failed to receive neither the on-site health check-ups nor the public health nurses' home visits (6.2\%). Individuals with a deteriorated competence in daily living could not take part in the follow-up health check-up at age 70 years, which might cause some selection biases. However, the baseline characteristics of the unfollowed participants were not much different from those of the participants of the present analyses. Secondly, we could not include important potential confounders such as cognition, hearing, and vision, because these data were not systematically collected. However, we consider the participants were apparently healthy without terrible dysfunctions in $\operatorname{cog}$ nition, hearing, and vision, because the participants of this research were all community-dwelling and walking in the health check-up at age 64 years. Lastly, it was impossible to obtain the outcome at age 70 years for the participants who died before 70 years of age. However, the directions of the risk/preventive factors for the decline in competence of daily living were not different by vital status in our preliminary analyses.

Because middle-aged and presenile adults are interested in maintaining their health, our results would be useful to them. In addition, our findings offer some ideas to healthcare providers and policymakers when they consider what to do for early elderly individuals or a little younger ones in order to help them to live well in their later years. By referring to our study results, healthcare workers could provide important information to the public and supply necessary care or services to those individuals who will benefit most.

\section{Conclusion}

In addition to known factors, living alone for men and low life satisfaction for women at age 64 years were markedly associated with the risk of declining competence in daily living during the subsequent 6 years among community-dwelling Japanese people. 


\section{Abbreviations}

ADL: Activities of daily living; Cl: Confidence interval; GDS: Geriatric Depression Scale; IADL: Instrumental activities of daily living; OR: Odds ratio TMIG-IC: Tokyo Metropolitan Institute of Gerontology Index of Competence

\section{Acknowledgements}

We thank the Health Center and Hygiene Department of Nisshin City for their cooperation.

\section{Funding}

This work was supported by JSPS KAKENHI Grant Numbers JP15390197 and JP26520105 and Mitsui Sumitomo Insurance Welfare Foundation.

\section{Availability of data and materials}

The data set analyzed for the current study is not publicly available because we did not obtain informed consent from the participants for the data use by persons except the researchers of the NISSIN project.

\section{Authors' contributions}

SO and TK contributed to the conception, analysis and interpretation of data, and preparation of manuscript. KW, MA, KT, HO, SU, and AT contributed to the design, acquisition of data, interpretation of data, critical review, and feedback. All authors read and approved the final manuscript.

\section{Ethics approval and consent to participate}

As we have written in the methods, for informed consent, an opt-out approach was adopted from 1996 to 2001 and individual written informed consent was obtained thereafter. The study was approved by the Ethics Committees of Nagoya University Graduate School of Medicine, the National Center for Geriatrics and Gerontology of Japan, Aichi Medical University of Medicine, and Hokkaido University Graduate School of Medicine.

\section{Consent for publication}

Not applicable.

\section{Competing interests}

The authors declare that they have no competing interests.

\section{Publisher's Note}

Springer Nature remains neutral with regard to jurisdictional claims in published maps and institutional affiliations.

\section{Author details \\ ${ }^{1}$ Kyoto University Health Service, Yoshida-Honmachi, Sakyo-ku, Kyoto 606-8501, Japan. ²Department of Preventive Medicine, Nagoya University Graduate School of Medicine, 65 Tsurumai-cho, Showa-ku, Nagoya 466-8550, Japan. ${ }^{3}$ Center for Advanced Medicine and Clinical Research, Nagoya University Hospital, 65 Tsurumai-cho, Showa-ku, Nagoya 466-8550, Japan. ${ }^{4}$ Aichi Comprehensive Health Science Center, 1-1 Aza Gengoyama, Oaza Morioka, Higashiura-cho, Chita-gun, Aichi 470-2101, Japan. ${ }^{5}$ Department of Psychology, Graduate School of Informatics, Nagoya University, Furo-cho, Chikusa-ku, Nagoya 464-8601, Japan. ${ }^{6}$ Research Unit of Advanced Interdisciplinary Care Science, Graduate School of Human Life Science, Osaka City University, 3-3-138, Sugimoto, Sumiyoshi-ku, Osaka 558-8585, Japan. ${ }^{7}$ Department of Public Health, Faculty of Medicine and Graduate School of Medicine, Hokkaido University, North 15, West 7, Kita-ku, Sapporo 060-8638, Japan}

Received: 12 February 2019 Accepted: 15 April 2019

Published online: 06 May 2019

\section{References}

1. World Population Prospects, The 2015 Revision. United Nations Department of Economic and Social Affairs, Population Division. 2015. https://esa.un.org/ unpd/wpp/publications/files/key_findings_wpp_2015.pdf. Accessed 11 Feb 2019.

2. Situation on Aging, Annual Report on the Aging Society: 2017. Cabinet Office. http://www8.cao.go.jp/kourei/english/annualreport/2017/2017pdf_e. html. Accessed 11 Feb 2019.
3. Annuanl Health, Labour and Welfare Report 2017. Ministry of Health, Labour and Welfare. https://www.mhlw.go.jp/english/wp/wp-hw11/index.html. Accessed 11 Feb 2019

4. Strawbridge WJ, Kaplan GA, Camacho T, Cohen RD. The dynamics of disability and functional change in an elderly cohort: results from the Alameda County Study. J Am Geriatr Soc. 1992:40:799-806.

5. Santoni G, Angleman S, Welmer AK, Mangialasche F, Marengoni A, Fratiglioni L. Age-related variation in health status after age 60. PLoS One. 2015:10:e0120077.

6. Lawton MP, Brody EM. Assessment of older people: self-maintaining and instrumental activities of daily living. Gerontologist. 1969;9:179-86.

7. Kurichi JE, Bogner HR, Streim JE, Xie D, Kwong PL, Saliba D, et al. Predicting 3-year mortality and admission to acute-care hospitals, skilled nursing facilities, and long-term care facilities in Medicare beneficiaries. Arch Gerontol Geriatr 2017:73:248-56.

8. Stuck AE, Walthert JM, Nikolaus T, Büla CJ, Hohmann C, Beck JC. Risk factors for functional status decline in community-living elderly people: a systematic literature review. Soc Sci Med. 1999;48:445-69.

9. Ishizaki T, Watanabe S, Suzuki T, Shibata H, Haga H. Predictors for functional decline among nondisabled older Japanese living in a community during a 3-year follow-up. J Am Geriatr Soc. 2000:48:1424-9.

10. Tomioka K, Kurumatani N, Hosoi H. Social participation and the prevention of decline in effectance among community-dwelling elderly: a populationbased cohort study. PLoS One. 2015;10:e0139065.

11. Kanamori S, Kai Y, Aida J, Kondo K, Kawachi I, Hirai H, et al. Social participation and the prevention of functional disability in older Japanese: the JAGES cohort study. PLoS One. 2014;9:e99638.

12. Tomioka K, Kurumatani N, Hosoi H. Association between social participation and 3-year change in instrumental activities of daily living in communitydwelling elderly adults. J Am Geriatr Soc. 2017:65:107-13.

13. Park M, Buchman AS, Lim AS, Leurgans SE, Bennett DA. Sleep complaints and incident disability in a community-based cohort study of older persons. Am J Geriatr Psychiatry. 2014;22:718-26.

14. Makizako H, Shimada H, Doi T, Tsutsumimoto K, Lee S, Hotta R, et al. Cognitive functioning and walking speed in older adults as predictors of limitations in self-reported instrumental activity of daily living: prospective findings from the Obu Study of Health Promotion for the Elderly. Int 」 Environ Res Public Health. 2015:12:3002-13.

15. León-Muñoz LM, Guallar-Castillón P, García-Esquinas E, Galán I, RodríguezArtalejo F. Alcohol drinking patterns and risk of functional limitations in two cohorts of older adults. Clin Nutr. 2017:36:831-8.

16. Gobbens RJ, van Assen MA. The prediction of ADL and IADL disability using six physical indicators of frailty: a longitudinal study in the Netherlands. Curr Gerontol Geriatr Res. 2014;2014:358137.

17. Davis MA, Neuhaus JM, Moritz DJ, Segal MR. Living arrangements and survival among middle-aged and older adults in the NHANES I epidemiologic follow-up study. Am J Public Health. 1992:82:401-6.

18. Schonberg MA, Li V, Marcantonio ER, Davis RB, McCarthy EP. Predicting mortality up to 14 years among community-dwelling adults aged 65 and older. J Am Geriatr Soc. 2017;65:1310-5

19. Tamakoshi A, Kawamura T, Wakai K, Ando M. Written informed consent for participation in a study and reduction in consent rate. J Epidemiol. 2008;18:291-4

20. Kitamura T, Kawamura T, Tamakoshi A, Wakai K, Ando M, Ohno Y. Rationale, design, and profiles of the New Integrated Suburban Seniority Investigation (NISSIN) Project: a study of an age-specific, community-based cohort of Japanese elderly. J Epidemiol. 2009;19:237-43.

21. Koyano W, Shibata H, Nakazato K, Haga H, Suyama Y. Measurement of competence: reliability and validity of the TMIG Index of Competence. Arch Gerontol Geriatr. 1991;13:103-16.

22. Burke WJ, Roccaforte WH, Wengel SP. The short form of the Geriatric Depression Scale: a comparison with the 30-item form. J Geriatr Psychiatry Neurol 1991:4:173-8.

23. Almeida OP, Almeida SA. Short versions of the geriatric depression scale: a study of their validity for the diagnosis of a major depressive episode according to ICD-10 and DSM-IV. Int J Geriatr Psychiatry. 1999;14:858-65.

24. Levasseur M, Richard L, Gauvin L, Raymond E. Inventory and analysis of definitions of social participation found in the aging literature: proposed taxonomy of social activities. Soc Sci Med. 2010:71:2141-9.

25. Wang H, Chen K, Pan Y, Jing F, Liu H. Associations and impact factors between living arrangements and functional disability among older Chinese adults. PLoS One. 2013:8:e53879. 
26. Connolly D, Garvey J, McKee G. Factors associated with ADL/IADL disability in community dwelling older adults in the Irish longitudinal study on ageing (TILDA). Disabil Rehabil. 2017;39:809-16.

27. Hughes $\mathrm{G}$, Bennett KM, Hetherington MM. Old and alone: barriers to healthy eating in older men living on their own. Appetite. 2004;43:269-76.

28. Hanna KL, Collins PF. Relationship between living alone and food and nutrient intake. Nutr Rev. 2015;73:594-611.

29. Tani $Y$, Kondo N, Takagi D, et al. Combined effects of eating alone and living alone on unhealthy dietary behaviors, obesity and underweight in older Japanese adults: results of the JAGES. Appetite. 2015;95:1-8.

30. Taylor SE, Klein LC, Lewis BP, Gruenewald TL, Gurung RA, Updegraff JA Biobehavioral responses to stress in females: tend-and-befriend, not fightor-flight. Psychol Rev. 2000;107:411-29.

31. Infurna FJ, Wiest M. The effect of disability onset across the adult life span. J Gerontol B Psychol Sci Soc Sci. 2018:73:755-66.

32. Matsushita A, Tahara M, Yoshimoto $H$. Why Japanese frail elderly men refuse social network?: a qualitative study. Off J Jpn Prim Care Assoc. 2015;38:34954 (article in Japanese with English abstract).

33. Asakawa T, Koyano W, Ando T, Shibata H. Effects of functional decline on quality of life among the Japanese elderly. Int J Aging Hum Dev. 2000;50: 319-28.

34. Enkvist $\AA$, Ekström $H$, Elmståhl S. Associations between functional ability and life satisfaction in the oldest old: results from the longitudinal population study Good Aging in Skåne. Clin Interv Aging. 2012;7:313-20.

35. Li CP. Life satisfaction as a predictor of mortality hazard among elderly people in the United Kingdom and Taiwan. J Nurs Res. 2013:21:26-38.

36. St John PD, Mackenzie C, Menec V. Does life satisfaction predict five-year mortality in community-living older adults? Aging Ment Health. 2015;19: 363-70

37. Bowling A, Grundy E. Differentials in mortality up to 20 years after baseline interview among older people in East London and Essex. Age Ageing. 2009; 38:51-5.

38. Oshio T. Gender differences in the associations of life satisfaction with family and social relations among the Japanese elderly. J Cross Cult Gerontol. 2012;27:259-74.

39. Yamazaki S, Nakano K, Saito E, Yasumura S. Prediction of functional disability by depressive state among community-dwelling elderly in Japan: a prospective cohort study. Geriatr Gerontol Int. 2012;12:680-7.

Ready to submit your research? Choose BMC and benefit from:

- fast, convenient online submission

- thorough peer review by experienced researchers in your field

- rapid publication on acceptance

- support for research data, including large and complex data types

- gold Open Access which fosters wider collaboration and increased citations

- maximum visibility for your research: over $100 \mathrm{M}$ website views per year

At $\mathrm{BMC}$, research is always in progress.

Learn more biomedcentral.com/submissions 